\title{
Reciprocal interplay of miR-497 and MALAT1 promotes tumourigenesis of adrenocortical cancer
}

\author{
Nunki Hassan 1,2, Jing Ting Zhao1,2, Anthony Glover1,2,3, Bruce G Robinson 1,2,4 and Stan B Sidhu ${ }^{1,2,3}$ \\ ${ }^{1}$ Cancer Genetics Laboratory, Kolling Institute, Northern Sydney Local Health District, Sydney, New South Wales, Australia \\ 2Sydney Medical School Northern, Royal North Shore Hospital, University of Sydney, Sydney, New South Wales, Australia \\ 3University of Sydney Endocrine Surgery Unit, Royal North Shore Hospital, Sydney, New South Wales, Australia \\ ${ }^{4}$ Department of Endocrinology, Royal North Shore Hospital and University of Sydney, Sydney, New South Wales, Australia
}

Correspondence should be addressed to S B Sidhu: stansidhu@nebsc.com.au

\begin{abstract}
Adrenocortical carcinoma (ACC) has high recurrence rates and poor prognosis with limited response to conventional cancer therapy. Recent contributions of highthroughput transcriptomic profiling identified microRNA-497 (miR-497) as significantly underexpressed, while IncRNA MALAT1 (metastasis-associated lung adenocarcinoma transcript 1) as overexpressed in ACC. miR-497 is located in the chromosomal region 17p13.1, in which there is a high frequency of loss of heterozygosity in ACC. We aim to investigate the interaction of miR-497 and MALAT1 in ACC and its functional roles in the process of tumourigenesis. In this study, we demonstrated miR-497 post-transcriptionally repressed MALAT1 while MALAT1 also competes for miR-497 binding to its molecular target, EIF4E (eukaryotic translation initiation factor $4 \mathrm{E}$ ). We showed that overexpression of miR-497 and silencing of MALAT1 suppressed cellular proliferation and induced cell cycle arrest through downregulation of EIF4E expression. Furthermore, MALAT1 directly binds to SFPQ (splicing factor proline and glutamine rich) protein, indicating its multifaceted roles in ACC pathophysiology. This is the first study to identify the feedback axis of miR-497-MALAT1/EIF4E in ACC tumourigenesis, providing novel insights into the molecular functions of noncoding RNAs in ACC.
\end{abstract} Key Words

- miR-497

- MALAT1

- microRNA

- long noncoding RNA

- adrenocortical carcinoma

\section{Introduction}

Adrenocortical carcinoma (ACC) is an ultra-rare and aggressive cancer with an incidence of $0.7-2.0$ cases per million populations (Kerkhofs et al. 2013). Its 5-year survival rate is lower than 35\% (Lughezzani et al. 2010). Surgical removal of the tumour is the first-line treatment and the best chance for long-term control of malignancy (Erdogan et al. 2013). However, approximately $50 \%$ of patients have recurrence 6-24 months after surgical resection (Libe 2015). For patients with advanced or metastatic disease, mitotane remains the only approved adrenolytic drug that is given in parallel with cytotoxic chemotherapy, but due to its limited response rates and long-term side effects, mitotane is not an effective treatment for most patients with ACC (Schteingart et al. 2012).

The traditional view of ncRNAs as merely transcriptional noise is fading and revolutionizing the basic concept of RNA carrying message for protein translation into a broader paradigm of gene regulation (c) 2019 Society for Endocrinology Published by Bioscientifica Ltd. Printed in Great Britain 
implicated in almost all biological pathways. The ncRNAs form ribonucleoprotein complexes that recognize nucleic acid target sequences through complementarity and consists of ncRNA of different sizes and functions (Kawaji \& Hayashizaki 2008). miRNAs are small ncRNAs approximately $\sim 21$ nucleotides in length that inhibit canonical target mRNAs translation or degrade mRNA transcript by binding to the $3^{\prime}$ untranslated regions (3' UTRs) of mRNA targets.

More than $50 \%$ of miRNA genes are located in cancer-associated genomic regions or in fragile sites, suggesting that miRNAs may play an important role in the pathogenesis of cancer (Calin et al. 2004). miRNA-497 (miR-497), part of miR-15 family cluster and encoded by the first intron of MIR497HG (Gene ID: 100506755), is located at the chromosomal region 17p13.1, in which there is a high frequency of loss of heterozygosity (LOH) in ACC compared to that of adrenocortical adenomas (Libe et al. 2007, Soon et al. 2008). Additionally, miR-497 was identified significantly underexpressed in three independent ACC studies (Ozata et al. 2011, Chabre et al. 2013, Assié et al. 2014).

Recent studies have also revealed miRNAs may interact with IncRNA to contribute to tumourigenesis (Wang et al. 2015, 2016, 2018). IncRNAs are eukaryotic RNA molecules greater than 200 nucleotides in length that have no or limited protein-coding capacity, however, may play a role in transcriptional interference, induce chromatin remodelling and histone modifications, modify alternative exon splicing as well as generate siRNAs (Wilusz et al. 2009). lncRNAs are tightly regulated by transcription factors and epigenetic chromatin modifications such as histone methylation, while their expression can be tissue and cell-type specific (Margueron \& Reinberg 2010, Mele \& Rinn 2016). IncRNAs can act as miRNA sponges by absorbing target miRNAs through their own miRNA reaction elements (MREs) and suppress the targeting mRNAs degradation mediated by miRNAs (Faghihi et al. 2010). Studies have also demonstrated that mature miRNAs regulate IncRNAs (Braconi et al. 2011, Leucci et al. 2013, Liang et al. 2013a). Conversely to IncRNAs miRNA sponging mechanism, they may also potentially serve as functional miRNA targets. Noncoding RNAs act in accordance with the current understanding of cancer as an interconnected network that presumably can only be successfully treated when intervening between multiple oncogenic and tumour-suppressive pathways. Thus investigating and understanding this ncRNA crosstalk will give an insight into gene regulatory networks and their implications in ACC.
lncRNA, metastasis-associated lung adenocarcinoma transcript 1 (MALAT1), was first discovered to be overexpressed in non-small-cell lung tumours (Ji et al. 2003). Mounting evidence also shows MALAT1 is overexpressed in a variety of different cancers such as hepatocellular carcinoma, breast, lung and gallbladder cancers (Lai et al. 2012, Ji et al. 2014, Feng et al. 2016, Sun et al. 2016, Zou et al. 2016). Moreover, patients with high levels of MALAT1 are at high risk of metastasis in hepatocellular carcinoma defining it as a prognostic marker (Lai et al. 2012). In our previous study of lncRNA microarray analysis in ACC, MALAT1 was found to be overexpressed in human ACC tissues and the ACC H295R cell line (Glover et al. 2015). As bioinformatics analysis of the MALAT1 sequence shows multiple putative binding sites for miR-497 (DIANA LncBase Predicted v.2, B.S.R.C Alexander Fleming, Athens, Greece), we aimed to investigate the interaction between miR-497 and MALAT1 as part of a mechanism underlying ACC tumourigenecity. We found MALAT1 as a bona fide target of miR-497 and exhibited the multifaceted roles of miR-497 and MALAT1 in ACC malignancy. Our study advances the role of lncRNAs and miRNAs in ACC biology and presents a further potential application of noncoding RNAs in ACC-targeted therapy.

\section{Materials and methods}

\section{Clinical tumour samples}

Both ACC and normal adrenal cortex (NAC) tissue samples used in this study was obtained from the Neuroendocrine Tumour Bank of the Kolling Institute of Medical Research with ethics approval from the Northern Sydney Area Health Service Human Research Ethics Committee. All patients consented to their samples being used in this study. NAC was harvested from patients by the surgeon whom had performed an adrenalectomy for a benign functional or non-functional adenoma. The normal adrenal was harvested away from the adenoma and adrenal medulla dissected off the cortex. The cortex was snap-frozen in liquid nitrogen and stored at $-80^{\circ} \mathrm{C}$ and histology confirmed by the pathologist prior to use as control tissue. ACC specimens were harvested by the surgeon at the time of surgery from solid areas of the tumour avoiding gross areas of necrosis. Before analysis a section of the frozen sample was analysed by a specialized endocrine pathologist using hematoxylin and eosin staining to exclude any samples with necrosis. 


\section{Cell culture and transfections}

Human ACC H295R cell line (CRL-2128) was purchased from American Type Culture Collection (ATCC) and cultured in Dulbecco's modified Eagle's medium (DMEM; Gibco) supplemented with $5 \%(\mathrm{v} / \mathrm{v})$ fetal bovine serum (FBS) and 1\% insulin transferrin selenium (ITS) supplement (Corning, Manassas, VA, USA).

To be able to manipulate the expression of miRNA-497, miRNA mimics (mirVana miRNA mimics, Thermo Fisher Scientific, cat no. 4464066), doublestranded (ds) mature miRNA-497, that function similarly to endogenous miRNA-497, were transfected into H295R cells at a final concentration of $40 \mathrm{nM}$ using Lipofectamine ${ }^{\circledR}$ RNAiMAX (Thermo Fisher Scientific) transfection reagent according to manufacturer's protocol. miRNA scramble sequences were used as negative controls (miR-NC). For miRNA transfections, cells were first transfected with $30-50 \%$ confluency, then transfected again 3 days after the first transfection. Cells were collected 3 days after the second completed transfection for the downstream phenotypic studies, including cell apoptosis, cell cycle analysis, cell invasion and migration assays.

MALAT1 silencing was performed through LNA $^{\mathrm{TM}}$ GapmeR (Exiqon, Vedbaek, Denmark), consisting of 14-16 DNA oligonucleotides that has enhanced affinity for the target MALAT1. LNA ${ }^{\mathrm{TM}}$ GapmeR were also transfected with a similar procedure as the miRNA mimics in H295R cells.

\section{Cell proliferation assay}

Cell proliferation was assessed by measuring the absorbance at $490 \mathrm{~nm}$ using CellTiter 96 Aqueous One Solution Cell Proliferation Assay according to the manufacturer's instruction (MTS Assay; Promega). ACC H295R cells, at a density of $5.0 \times 10^{3}$ cells per well in a flatbottomed 96-well plate, were first reverse transfected with miRNA mimics, and then transfected again three days after the first transfection. The day with the completed second transfection was labelled as day 0 and cell proliferation was assessed on the following days 3, 4, 7 and 8 .

\section{Cell cycle and apoptosis analysis}

For cell cycle analysis, $1.0 \times 10^{6} \mathrm{H} 295 \mathrm{R}$ cells were stained with propidium iodide (PI; Sigma Aldrich) at a final concentration of $17.4 \mu \mathrm{g} / \mathrm{mL}$ and the cells were analysed using fluorescence-activated cell sorting (FACS) technique (FACS Calibre, BD Biosciences), flow cytometry histograms were modelled using Modfit LT software (Verity Software
House, ME, USA). For apoptosis analysis, PE Annexin V apoptosis detection kit was used (BD Pharmigen, San Diego, USA) according to manufacturer's instructions on day 4 post transfection. Early-stage apoptosis was determined by Annexin V positive and PI-negative cells on apoptosis graph of FACS assay. Late-stage apoptosis was measured by Annexin V-positive and PI-positive cells.

\section{Invasion and migration}

The Cytoselect ${ }^{\mathrm{TM}}$ 24-well cell invasion and migration (Cell Biolabs, Inc., San Diego, CA, USA) were used for the cell invasion assay in accordance with the manufacturer's protocol. Briefly, $2.5 \times 10^{4}$ cells in serum-free DMEM were added to the upper chamber of the Matrigel-coated insert, and $500 \mu \mathrm{L}$ of DMEM containing $5 \% \mathrm{FBS}+1 \%$ ITS was added to the lower chamber for culture. The cells were cultured in a humidified atmosphere for $48 \mathrm{~h}$ at $37^{\circ} \mathrm{C}$ and $5 \% \mathrm{CO}_{2}$, and the non-invading cells were removed. The cells were stained using cell stain solution (Cell Biolabs, Inc.) for $10 \mathrm{~min}$ at room temperature. The invading cells were extracted using Extraction Solution (Cell Biolabs, Inc.) and measured at OD $560 \mathrm{~nm}$ in a plate reader (Synergy ${ }^{\mathrm{TM}}$, Winooski, VT, USA). Migration assays were applied similarly and migrating cells were stained, extracted and measured at $24 \mathrm{~h}$.

\section{RNA extraction and RT-qPCR}

Total RNA was isolated from tumour tissues, H295R cells using a Qiazol protocol (miRNeasy Mini Kit; Qiagen) and with the RNA quality and concentration tested by the NanoDrop ${ }^{\circledR}$ (ND-1000 spectrophotometer). miR-497 expression profile was validated in a local series of ACC and NAC tissues. The expression level of miRNA-497 day 3 post transfection was measured via quantitative reverse transcription-PCR (RT-qPCR) by using TaqMan ${ }^{\circledR}$ MicroRNA cells-to- $\mathrm{C}_{\mathrm{T}}^{\mathrm{TM}}$ kit (Applied Biosystems) and commercially available TaqMan ${ }^{\circledR}$ stem-loop RT primers (Applied Biosystems). 10 ng of total RNA were first reversetranscribed to cDNA using TaqMan miRNA primers. The reverse transcriptase reaction conditions were $30 \mathrm{~min}$ at $16^{\circ} \mathrm{C}, 30 \mathrm{~min}$ at $42^{\circ} \mathrm{C}$, the reactions were then terminated for $5 \mathrm{~min}$ at $85^{\circ} \mathrm{C}$ and chilled at $4^{\circ} \mathrm{C}$ (Applied Biosystems). The quantitative real-time PCR was performed using the ABI 7900HT Real-time PCR System (Applied Biosystems) under the standard PCR conditions: $2 \mathrm{~min}$ at $50^{\circ} \mathrm{C}$, then 40 cycles of $15 \mathrm{~s}$ at $95^{\circ} \mathrm{C}$ and $60 \mathrm{~s}$ at $60^{\circ} \mathrm{C}$. RNU48 was used as a reference gene for human clinical samples for miRNA profiling. 
The same method was also used for gene expression of mRNA targets. Approximately $1 \mu \mathrm{g}$ of total RNA was used to synthesize cDNA using RNA-to-cDNA Reverse Transcription (Applied Biosystems) and subjected to quantitative realtime PCR reaction conditions: $5 \mathrm{~min}$ at $95^{\circ} \mathrm{C}$, and 40 cycles of $10 \mathrm{~s}$ at $95^{\circ} \mathrm{C}$ and $20 \mathrm{~s}$ at $60^{\circ} \mathrm{C}$. PCR was amplified using standard TaqMan gene expression assays (Life Technologies). Target gene expression was normalized to the expression of GAPDH within each sample using the relative $\Delta \Delta \mathrm{CT}$ method (Livak \& Schmittgen 2001). The quantitative realtime PCR was performed using the ABI 7900HT Real-time PCR System (Applied Biosystems) under the standard PCR conditions. Relative expression (RQ) was obtained using the $\Delta \Delta \mathrm{Ct}$ method and the differences between groups were assessed using DataAssist version 3.01 (Applied Biosystems).

\section{Luciferase reporter assays}

To verify that EIF4E is directly regulated by miR-497, a luciferase reporter assay was performed. miR-497 putativebinding sites in the 3 '-untranslated region (3'-UTR) regions of EIF4E were amplified from human genomic DNA by PCR and cloned into the pMIR-REPORT Luciferase Vector (Part Number AM5795, Life Technologies) between SpecI and SacI restriction sites.

For the EIF4E-3' UTR reporter, primer sequences as below were used to amplify a fragment of $830 \mathrm{bp}$ containing two predicted miR-497 seed-binding sequences.

Forward primer: 5'-GACTACTAGTAAATGTGTTCCT GGCCCACTC-3'

Backward primer: 5'-GACTGAGCTCTGTTCACATGG AAGACACCAC-3'

For the MALAT1 reporter, primer sequences as below were used to amplify a fragment of $849 \mathrm{bp}$ also containing two seed-binding sequences for miR-497.

Forward primer: 5'-(GCAGCCCGAGACTTCTGTAAA GG)-3' TC)-3'

Backward primer: 5'-(GTGGCAAAATGGCGGACTT

For the reporter assay, the H295R cells were co-transfected along with $50 \mathrm{ng}$ of pMIR Luciferase Reporter Vector, Renilla Luciferase Control Vector (Promega), and $40 \mathrm{nM}$ of miR-497 mimics or doublestranded NC using Lipofectamine 2000 reagent (Thermo Fisher) using manufacturer's protocol. Luciferase activity was measured 2 days after transfection using the DualLuciferase Reporter Assay System (Promega) using a luminometer (Veritas Microplate Luminometer, Turner Biosystems, CA, USA). Relative firefly luciferase activity was normalized to the activity of Renilla luciferase activity.

\section{RNA-binding protein immunoprecipitation}

RNA immunoprecipitation can be used to identify any RNA species through co-isolation of associated nuclear or cytoplasmic endogenously formed complexes of RNA-binding proteins. Purification of these RNA species also allows interrogation and identification of potential IncRNAs associated with them and can be directly measured downstream using RT-qPCR. RNA-binding protein immunoprecipitation (RIP) was made according to the manufacturer's protocol from the EZ-Magna RIP Kit (EMD Millipore) day 3 post transfection. Approximately, $2 \times 10^{7} \mathrm{H} 295 \mathrm{R}$ cells were lysed in RIPA lysis buffer at $-80^{\circ} \mathrm{C}$ overnight. The samples were then centrifuged at $14,000 \boldsymbol{g}$ for $10 \mathrm{~min}$ to pellet insoluble protein and the supernatant was collected. Magnetic beads binding antibody of interest for immunoprecipitation were prepared. Mouse SFPQ antibody (sc-101137, Santa Cruz Biotechnology) and nonspecific mouse IgG antibody were used. The RIP lysates and magnetic beads-binding antibody of interest were incubated together rotating overnight at $4^{\circ} \mathrm{C}$ leading to the immunoprecipitation of RNA-binding proteinRNA complex. Each immunoprecipitate was digested with proteinase $\mathrm{K}$ and $10 \% \mathrm{SDS}$ at $55^{\circ} \mathrm{C}$ for $30 \mathrm{~min}$ after washing with RIP washing buffer. After incubation, centrifuge was used to obtain the supernatant, followed by washing and adding phenol:chloroform:isoamyl alcohol (125:24:1) to separate the phases. Chloroform was added to separate the aqueous phase from the chloroform, and $80 \%$ ethanol was used to precipitate the RNA. Each sample was reversetranscribed using the High Capacity RNA-to-cDNA Kit (Applied Biosystems), followed by qPCR and analysis. All assays were performed in triplicate and independently repeated three times.

\section{Statistics}

All numerical results were expressed as the mean \pm S.D. Statistical significance between groups was determined using a paired Student's $t$-test, which was performed using Graph Pad Prism (version 7.0b).

\section{Results}

miR-497 is underexpressed in ACC

To confirm the underexpression of miR-497 in ACC, RT-qPCR was performed on an independent cohort of 19 ACC and 10 NAC tissue samples. This analysis showed that miR-497 was significantly underexpressed in ACC 
A

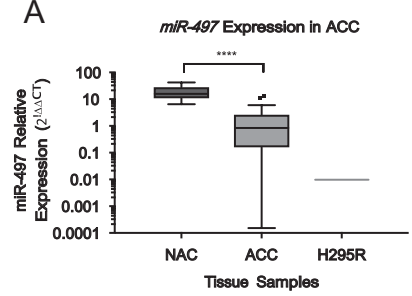

D

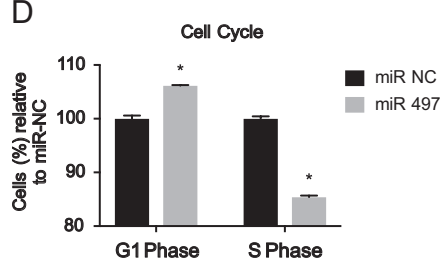

B

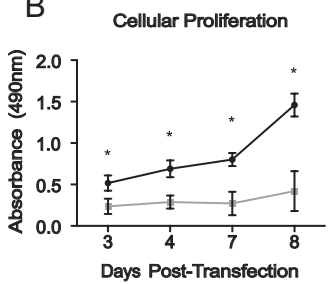

E

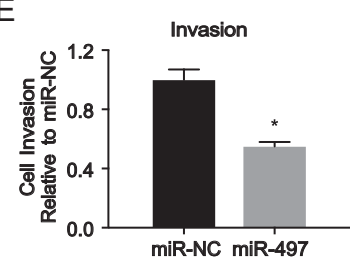

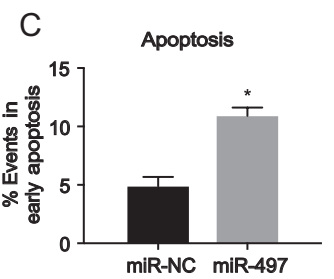

$\mathrm{F}$

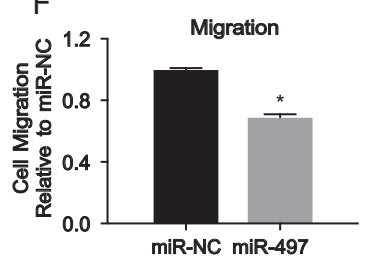

Figure 1

miR-497 exerts tumour suppressive roles in ACC. (A) miR-497 is underexpressed in ACC tumour samples compared to NAC. There is also a reduction of miR-497 expression in ACC H295R cell line $(n=3)$. Data are presented as Tukey box plot; median expression is represented by the solid line within the box and the outliers are represented by the dots outside the boxes. (B) miR-497 replacement had growth inhibition in H295R cells. (C) Extra 5\% of cellular events underwent early apoptosis post transfection of miR-497 when compared to miR-NC. (D) miR-497 increased cell percentage in the G1 phase by $6 \%$ cells. miR-497 decreased cell percentage in the S phase by 15\%. (E) Significant decrease in cell invasion by $44 \%$ following miR-497 replacement. (F) miR-497 reduced migration by 31\% compared to miR-NC. Error bars show S.D., $n=3$. $* P<0.05, \star \star \star \star P<0.0001$.

with a 23-fold reduction compared to NAC (Fig. 1A). miR-497 was also underexpressed in ACC H295R cells compared to NAC tissues (Fig. 1A).

\section{miR-497 promotes tumour-suppressive functions in ACC}

The functional roles of endogenous miR-497 in the pathogenesis of ACC were investigated upon the replacement of miR-497. The restoration of miR-497 expression in $\mathrm{H} 295 \mathrm{R}$ cells following transfection of miR-497 mimics was confirmed using RT-qPCR (Supplementary Fig. 1, see section on supplementary data given at the end of this article). Restoration of miR-497 resulted in significant inhibition of cell proliferation in H295R cells when compared to miR-NC $(P<0.05)$ (Fig. 1B). The greatest reduction in the inhibition of cell growth was identified on days 7 and 8 with a decrease in cellular proliferation by 73 and 83\%, respectively.

The effect of miR-497 on cell apoptosis and cell cycle was further investigated. The Annexin-7AAD staining method demonstrated that the early-stage apoptosis was increased by $5 \%$ following transfection with the miR- 497 mimics $(P<0.05)$ (Fig. 1C). There was no difference in latestage apoptosis when miR-497 treated was compared to miR-NC (data not shown). Cell cycle analysis demonstrated cells transfected with miR-497 had significantly increased cell percentage in G1 phase and reduced in $\mathrm{S}$ phase when compared to miR-NC (Fig. 1D).

(c) 2019 Society for Endocrinology Published by Bioscientifica Ltd. Printed in Great Britain
Subsequently, we analysed the effects of miR-497 on the migration and invasion ability of ACC cells. Using transwell assays, we observed that both the invasive (Fig. 1E) and migratory (Fig. 1F) activities of ACC cells were suppressed with miR-497 by 44 and 31\%, respectively $(P<0.05)$.

\section{miR-497 targets IncRNA MALAT1 expression through direct binding}

To further confirm the direct interaction of miR-497 and MALAT1, we cloned fragments of MALAT1 encompassing two putative-binding sites into the multiple cloning sites of the pMIR-REPORT miRNA Expression Reporter Vector (Fig. 2A). The H295R cells were co-transfected with miR-497 mimics along with the pMIR-REPORT reporter vector, and miR-497 overexpression resulted in a significant decrease in luciferase activity when compared to miR-NC (Fig. 2B).

Furthermore, miR-497 overexpression reduced transcripts of MALAT1 in H295R cells (Fig. 2C). We were also interested to observe if MALAT1 acted as a miR-497 sponge, by knocking down MALAT1 and subsequently performing RT-qPCR to measure the expression of miR-497. There was an increase in miR-497 expression after silencing MALAT1; however, it did not reach statistical significance in miR-497 expression after MALAT1 knockdown compared with miR-NC (Fig. 2D). 

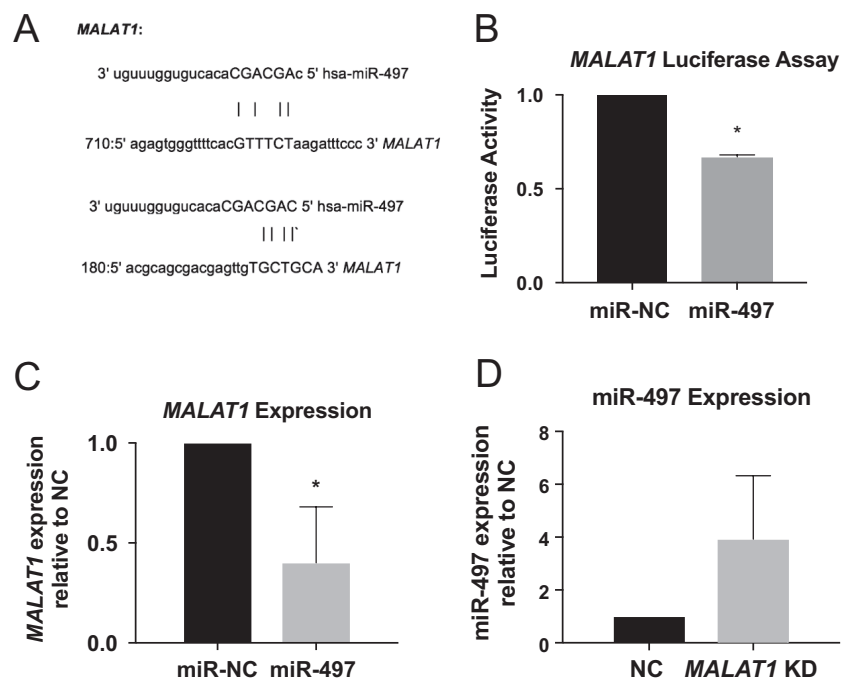

\section{Figure 2}

miR-497 targets IncRNA MALAT1. (A) Putative miR-497 seed-binding sites of targets in IncRNA MALAT1. (B) Co-transfection of the luciferase reporter vector containing potential binding region for of MALAT1, respectively along with miR-497 mimics suppressed luciferase activity compared to miR-NC. (C) Following miR-497 replacement in H295R cells, reduced mRNA expression of MALAT1 was detected compared to miR-NC-treated cells. (D) Following MALAT1 knockdown in H295R cells, changes in miR-497 was increased by a fold change of $\sim 4$. Error bars show S.D., $n=3$. ${ }^{\star} P<0.05$.

\section{MALAT1 knockdown induced growth inhibition and G2/M cell cycle arrest}

LNA $^{\text {TM }}$ GapmeR against MALAT1 was used to silence MALAT1 in the H295R cells while scramble sequences of LNA ${ }^{\mathrm{TM}}$ GapmeR was used as a NC. Reduced MALAT1 expression was confirmed by RT-qPCR following transfection of MALAT1 LNA ${ }^{\mathrm{TM}}$ GapmeRs (Fig. 3A). Knockdown of MALAT1 resulted in significant inhibition of cell proliferation in $\mathrm{H} 295 \mathrm{R}$ cells from days 4 to 6 post transfection $(P<0.05$, Fig. $3 \mathrm{~B})$. Cell cycle analysis demonstrated that cells with reduced MALAT1 had significantly increased cell percentage in G2 phase and reduced percentage in G1 phase when compared to NC $(P<0.05$, Fig. 3C).

\section{Molecular functions of MALAT1}

To further understand the function of MALAT1 in ACC, we reviewed known targets of MALAT1. Several studies have revealed that MALAT1 binds to SFPQ (splicing factor proline and glutamine rich) protein, mediating transcription of downstream pro-oncogenes such as PTBP2 (polypyrimidine-tract-binding protein also known as SFPQ binding protein) and GAGE6 (G antigen 6) (Ji et al. 2014, Hu et al. 2018).

In our previous study of focused lncRNA/mRNA transcriptome analysis in ACC (Glover et al. 2015), SFPQ was shown to be significantly underexpressed in ACC compared with NAC. This was further validated on an independent cohort of eight ACC and eight NAC in this study using RT-qPCR, demonstrating a significant reduction of four-fold in ACC compared to NAC (Fig. 4A). SFPQ was also underexpressed in ACC H295R cells compared to NAC tissues (Fig. 4A). We also found an upregulation of SFPQ mRNA transcript after MALAT1 knockdown (Fig. 4B) but no protein expression change was identified.

In this study, RIP assay using SFPQ antibody to pull down the IncRNA/protein complex detected MALAT1 transcript. In studying the impact of MALAT1 expression on the binding of MALAT1 and SFPQ, we found that MALAT1 binding to SFPQ was decreased in MALAT1knockdown cells when compared to NC (Fig. 4C). Ten percent input control had the highest level of MALAT1 with 2500-fold enrichment, followed by NC with 600-fold enrichment. MALAT1 fold enrichment was normalized to the IgG control. These results indicated that MALAT1 directly binds to the SFPQ protein in H295R cells (Fig. 4C).
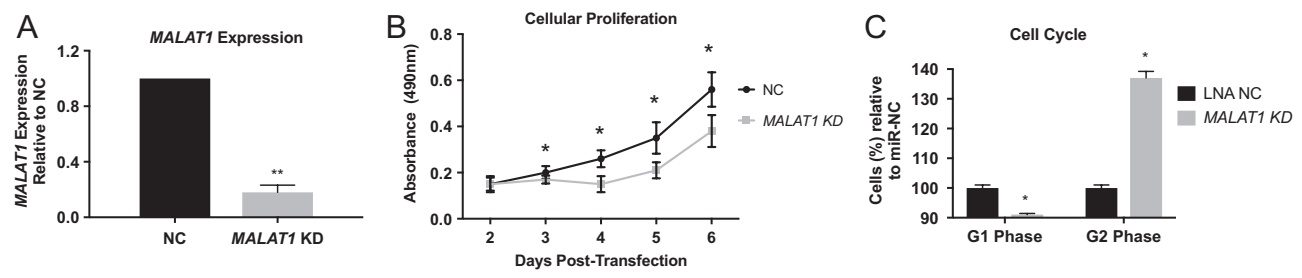

Figure 3

MALAT1 knockdown induced growth inhibition and cell cycle arrest in ACC. (A) MALAT1 transcript was reduced by $\sim 80 \%$ following the transfection of MALAT1 LNA ${ }^{\text {TM }}$ GapmeRs, detected by RT-qPCR. (B) Silence of MALAT1 caused a significant growth inhibition in H295R cells. (C) MALAT1 knockdown induced cell cycle arrest in $\mathrm{H} 295 \mathrm{R}$ cell line with $\sim 10 \%$ reduction in cells going through $\mathrm{G} 1$ phase and an increase of $\sim 35 \%$ cells entering the G2 phase. Error bars show S.D., $n=3 . * P<0.05, * * P<0.01$. 
A

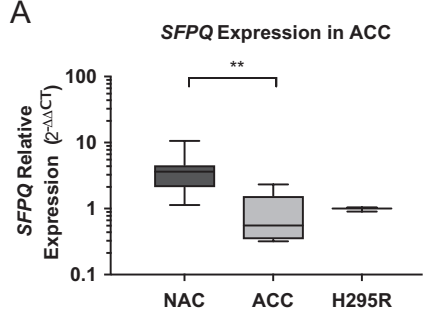

D

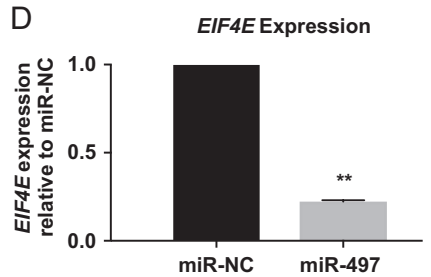

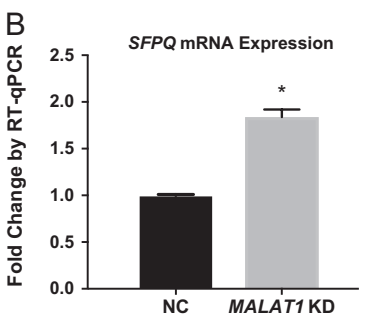

C
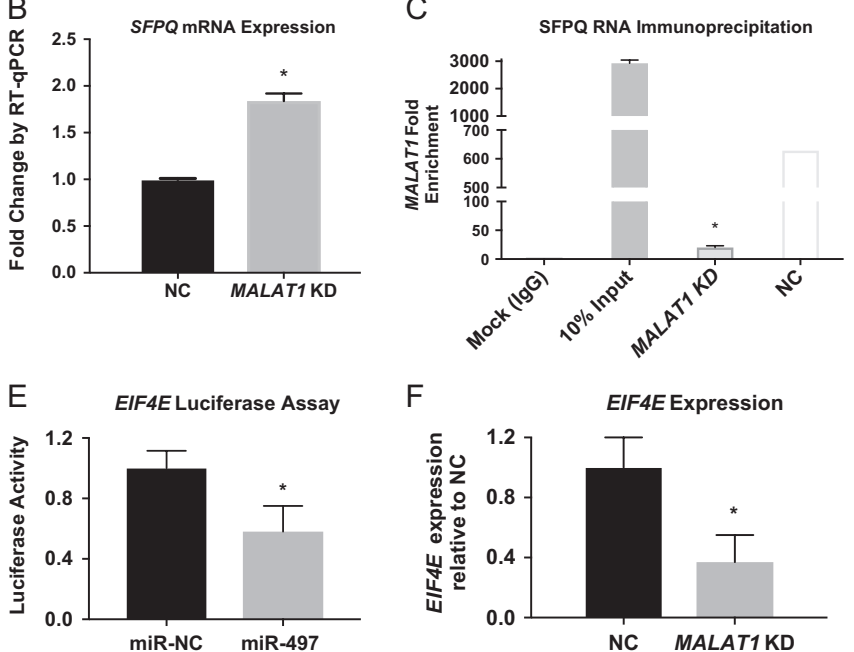

$\mathrm{F}$

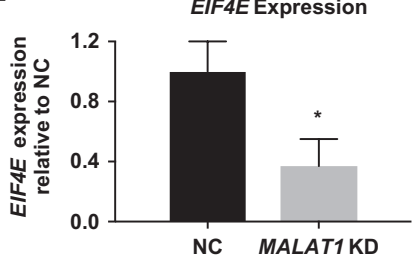

Figure 4

Functional effects of miR-497 and MALAT1 on cancer-related genes. (A) SFPQ is underexpressed in ACC tissues compared to NAC. There is also a reduction of SFPQ expression in ACC H295R cells $(n=3)$. The data are presented as Tukey box plot; median expression is represented by the solid line within the box. (B) The expression of SFPQ mRNA transcript was increased by 1.8-folds in H295R cells following MALAT1 knockdown. (C) RNA immunoprecipitation with SFPQ antibody followed by RT-qPCR to examine MALAT1 expression. Data were normalized to mouse IgG as negative control (MALAT1 expression equals to 1). (D) miR-497 overexpression reduced the levels of EIF4E by $78 \%$. (E) Co-transfection of the luciferase reporter vector containing 3' UTR of EIF4E, respectively along with miR-497 mimics suppressed luciferase activity. (F) MALAT1 knockdown reduced levels of EIF4E mRNA expression by 63\%. Bioinformatics tools including Miranda, TargetScan and Diana Tools were utilized to determine putative miRNA targets. Total RNA was collected from H295R cells following day 3 post transfection. mRNA

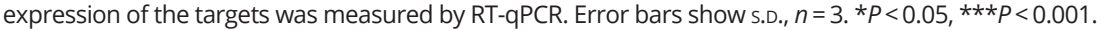

\section{MALAT1 competes for miR-497 binding to its molecular targets}

To further investigate whether molecular targets of miR-497 may interact with MALAT1 in ACC, we first sought to identify mRNA targets of miR-497. We cross referenced putative targets of miR-497 using several prediction algorithm tools; DIANA-microT-CDS version 5.0 (B.S.R.C Alexander Fleming, Athens, Greece), DIANA-miRPath version 6.0 (B.S.R.C. Alexander Fleming), miRanda (Memorial Sloan-Kettering Cancer Centre, NY, USA) and TargetScan version 7.1 (Whitehead Institute for Biomedical Research, MA, USA). While SFPQ is not a putative target of miR-497, we identified a number of potential miR-497 targets for further validation. Selected putative targets derived from major cancer-related signalling pathways are listed in Supplementary Table 1.

Restoration of miR-497 significantly reduced mRNA transcripts of eukaryotic initiation factor $4 \mathrm{E}$ (EIF4E) by 4.5-fold in H295R cells (Fig. 4D). Furthermore, knockdown of MALAT1 also significantly reduced mRNA transcripts of EIF4E by 2.7-fold change when compared to NC $(P<0.05)$ (Fig. 4F).

The 3'-UTR sequence of EIF4E containing the potential binding sequences for miR-497, were further cloned into the multiple cloning sites of the pMIR-REPORT miRNA
Expression Reporter Vector (Supplementary Fig. 2). The H295R cells were co-transfected with miR-497 mimics or miR-NC along with the pMIR-REPORT reporter vector and the luciferase activity was measured. The experimental results showed that the miR-497 mimics downregulated the luciferase activity of the luciferase reporter (Fig. 4E) when compared to miR-NC. This confirms the direct binding of miR-497 with EIF4E. These results further support the potential role of MALAT1 acting as miR-497 sponge whereby knockdown of MALAT1, relieving the competition for miR-497 binding to EIF4E, led to the reduction of EIF4E.

\section{Discussion}

We report for the first time the reciprocal interplay of miRNA and lncRNA in ACC and its critical roles during the tumourigenic process. This study demonstrates miR-497 functions as a tumour suppressor through post-transcriptional repression of IncRNA MALAT1 while MALAT1 also competes for miR-497 binding to its molecular targets. We have shown that overexpression of miR-497 and silencing of MALAT1 indeed suppressed cell proliferation by inducing cell cycle arrest by regulating 
EIF4E expression. Furthermore, we have identified the feedback axis of miR-497-MALAT1/EIF4E promotes the tumourigenesis in ACC.

miR-497 is a highly conserved miRNA, located on the human chromosome 17p13.1, the genomic locus for p53. miR-497 belongs to the miR-15 family which includes miR-15a, miR-15b, miR-16-1/2, miR-195 and miR-424 and shares the same 3' UTR-binding seed sequence (AGCAGCA). High frequencies of $\mathrm{LOH}$ in the region of chromosome 17p13.1 and its association with malignancy have been described in ACC (Libe et al. 2007, Soon et al. 2008). However, there was no significant driver gene that has been identified in the region for ACC tumourigenesis (Libe et al. 2007). It was previously shown that LOH in this region implicated TP53; however, both the latest comprehensive whole genome studies of ACC revealed only 16 and $17.8 \%$, respectively of ACC were mutated in the TP53 gene (Assié 2014, Zheng et al. 2016).

We have previously demonstrated in a significant body of work that there is a minimum $10.4 \mathrm{Mb} \mathrm{LOH}$ in ACC compared to adrenal adenoma (Soon et al. 2008). In that study the region of 17p13.1-13.3 were fine-mapped utilising 12 microsatellite markers in 23 ACCs and 14 adenomas demonstrating $\mathrm{LOH}$ in $74 \%$ of cancers and only $14 \%$ of adenomas. This region of $\mathrm{LOH}$ contains the TP53 gene and miR-497 and we surmise that 497 is a key tumour suppressor gene lost in this region in three quarters of adrenal cancers. This finding by Soon et al. is consistent with the current study demonstrating a significant reduction in the expression of miR-497 in the current cohort of ACCs compared to normal adrenal and is analogous to the initial discovery of miR-15a/16 as tumour suppressor genes as they were underexpressed in chronic lymphatic leukaemia (CLL) and located at $13 q 14$ - a region that was frequently deleted in CLL (Calin et al. 2002).

miR-497 has been identified to act as a potential tumour suppressor in various cancers (Li et al. 2011, Shen et al. 2012, Furuta et al. 2013, Luo et al. 2013, Wang et al. 2013, Ma et al. 2017). Further studies to investigate the high frequencies of $\mathrm{LOH}$ and its association with the underexpression of miR-497 in ACC may help to characterize the tumour-suppressive roles of miR-497 as a driver in ACC.

The interaction network of miRNA-mRNA-lncRNA has been revealed to play critical regulatory roles in cancer biology (Xiao et al. 2015, Lu et al. 2016, Wang et al. 2017). MALAT1 has been reported that it modulates splicing factors and regulates alternative splicing of a subset of pre-mRNAs, however, upstream control of
MALAT1 has not been elucidated (Tripathi et al. 2010). Accumulating studies have shown some lncRNAs are under the regulation of miRNAs to reduce their stability. For example, oncogenic lncRNA HOTTIP is frequently upregulated in hepatocellular carcinoma and post-transcriptionally targeted by tumour suppressive miR-125b (Tsang et al. 2015). MALAT1 has also been found to be silenced by miR-101 and miR-217 in oesophageal squamous cell carcinoma, which leads to significant reduction of cell proliferation by the G2/M cell cycle arrest (Wang et al. 2015). More studies have shown that lncRNAs interact with miRNA by competing for miRNAs binding to their downstream mRNA targets (Cesana et al. 2011, Tay et al. 2011, Feng et al. 2016, Wu et al. 2017). An in vitro study in gallbladder cancer, demonstrated MALAT1 could directly bind to miR-363-3p and effectively function as a miRNA sponge to modulate the expression of its endogenous target myeloid cell leukaemia-1 (MCL-1) (Wang et al. 2016). In hepatocellular carcinoma, MALAT1 also functions as a competing endogenous RNA for miR-30a-5P to regulate vimentin and promotes migration and invasion (Pan et al. 2018).

In our published study (Glover et al. 2015), MALAT1 was previously assessed to be overexpressed in ACC in a discovery cohort of ten ACCs compared to six NACs and consequently validated in an expanded cohort of 20 ACCs and six NACs. In this study, we confirmed the underexpression of miR-497 and identified not only miR-497 negatively regulates the expression of MALAT1, and MALAT1 also reversely competes for miR-497 binding to EIF4E, alleviating the negative effect of miR-497 on EIF4E.

The expression and activation of EIF4E has been reported to be associated with transformation and tumourigenesis while acting as a proto-oncogene in cancers (Wendel et al. 2004, Graff et al. 2008). In gastric and breast cancer, downregulation of EIF4E resulted in the reduction in proliferation and cell cycle arrest in vitro (Liang et al. 2013b, Nasr et al. 2013). We also found that restoration of miR-497 significantly slowed proliferation and arrested cell cycle partially by regulating the expression of EIF4E in H295R cells. In our next phase of study, it would be interesting to explore the direct effect of EIF4E regulation on the development of ACC by examining the loss-of-function studies in H295R cells using gene editing to silence the EIF4E gene transcript. Overall, our findings in this study suggest that the feedback axis of miR-497MALAT1/EIF4E, as demonstrated in Fig. 5, may act as a key mediator in the tumourigenesis of ACC, providing novel insights into the molecular functions of noncoding RNAs in ACC. 


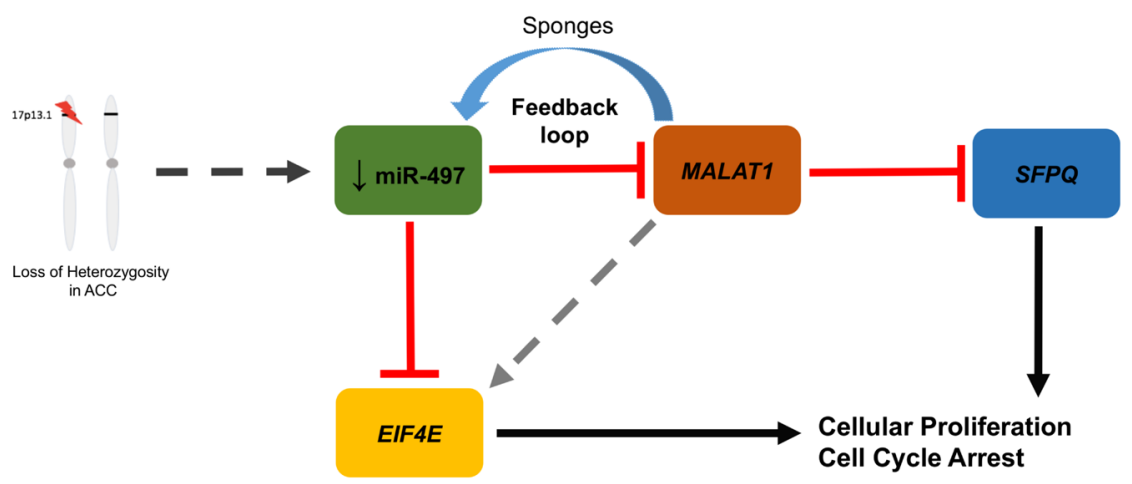

\section{Figure 5}

Schematic of miR-497-MALAT1/EIF4E interplay feedback axis. LOH at 17p13.1 as shown in Libe et al. (2007) leads to the underexpression of miR-497. This affects the feedback loop between miR-497 and MALAT1 and their downstream targets, EIF4E and SFPQ, which regulates cellular proliferation and cell cycle arrest. A full colour version of this figure is available at https://doi. org/10.1530/ERC-19-0036.

This study is the first to show the reciprocal relationship between miR-497 and MALAT1. Such effect has not been previously studied in a non-adrenal cell line. However, bioinformatics platform, Diana Tools LncBase Predicted v.2 (B.S.R.C Alexander Fleming), identifies that MALAT1 sequences contain putative binding sites for miR-497, demonstrating its potential interaction in other cell types. In a study of hepatocellular carcinoma (HCC) (Yan et al. 2018), expression of miR-497 and MALAT1 was identified to be inversely correlated; yet, this study did not show the direct interaction between miR-497 and MALAT1.

Alternative putative targets of miR-497 have been studied in other cancers. For example, the WEE1 G2 checkpoint kinase (WEE1) gene has been experimentally validated in the study of neuroblastoma (Creevey et al. 2013). However, we did not detect any change in the mRNA expression of WEE1 following restoration of miR-497 in the ACC cells. Some other molecular targets, such as Inhibitor of nuclear factor kappa-B kinase subunit beta $(I K K \beta)$ gene and Wnt family member 7A (WNT7A) gene have also been validated in prostate cancer and bladder cancer, respectively (Itesako et al. 2014, Kong et al. 2015). These molecular targets are critical to tumour progression and their examination in H295R cells may further reinforce the tumour-suppressive roles of miR-497 in ACC. For a more complete analysis, whole transcriptome profiling using RNAseq will likely identify further molecular targets of miR-497 to enhance the understanding of the roles of miR-497 in ACC development.

IncRNA MALAT1 has been reported to show extensive regulatory functions in cell proliferation, migration and invasion in various cancers (Hirata et al. 2015, Feng et al. 2016, Gu et al. 2017). Although the oncogenic roles of overexpression of MALAT1 is not yet fully understood, it has been identified that MALAT1 is associated with SFPQ, promoting the process of tumourigenesis. SFPQ is a DNA- and RNA-binding protein, involved in transcriptional regulation. In colorectal cancer (CRC), MALAT1 competitively binds to SFPQ and releasing PTBP2 (polypyrimidine-tract-binding protein) from the SFPQ/PTBP2 complex to promote cell growth and migration (Ji et al. 2014). In a similar pattern in lung adenocarcinoma, hypoxia exposure upregulated the expression of MALAT1, which binds to SFPQ and releases it from the GAGE6 promoter, leading to the promotion of cell proliferation, migration and invasion ( $\mathrm{Li}$ et al. 2009). Our data demonstrated MALAT1 is overexpressed in ACC and can directly bind to SFPQ, although the detail of the binding location still needs further investigation in ACC cells.

In addition to SFPQ, some other molecular targets of MALAT1 have been studied in ovarian and cervical cancers. For example, apoptotic markers such as Bcl-2associated X protein (BAX) and B-cell lymphoma (BCL2) were downregulated by MALAT1 in ovarian cancer (Bai et al. 2018). MALAT1 particularly promoted proliferation and invasion by stimulating the expression of caspase- 3 and caspase- 8 and inhibiting expression of BCL2 in cervical cancer (Guo et al. 2010). This warrants further investigation of these additional molecular targets in H295R cells to assess the other roles of MALAT1 in ACC.

In summary, this study demonstrates miR-497mediated regulation of lncRNA MALAT1, and inversely MALAT1 may potentially act as a miR-497 spongereleasing downstream oncogenic targets. The feedback loop between miR-497 and MALAT1 could functionally reduce cell proliferative effects and induce cell cycle arrest by mediating EIF4E expression. Our data provide new insights into the molecular mechanisms of ACC tumourigenicity in the context of noncoding RNAs.

\section{Supplementary data}

This is linked to the online version of the paper at https://doi.org/10.1530/ ERC-19-0036.
(C) 2019 Society for Endocrinology Published by Bioscientifica Ltd. Printed in Great Britain 


\section{Declaration of interest}

The authors declare that there is no conflict of interest that could be perceived as prejudicing the impartiality of the research reported.

\section{Funding}

S B Sidhu is a Sydney Medical School Foundation Fellow (University of Sydney). Nunki Hassan is a PhD candidate funded by the Sydney Medical School Foundation Postgraduate Research Scholarship. This project was also funded by Sydney Vital Translational Cancer Research and EnGenelC Cancer Research Foundation.

\section{References}

Assié G, Letouzé E, Fassnacht M, Jouinot A, Luscap W, Barreau O, Omeiri H, Rodriguez S, Perlemoine K, René-Corail F, et al. 2014 Integrated genomic characterization of adrenocortical carcinoma. Nature Genetics 46 607-612. (https://doi.org/10.1038/ng.2953)

Bai L, Wang A, Zhang Y, Xu X \& Zhang X 2018 Knockdown of MALAT1 enhances chemosensitivity of ovarian cancer cells to cisplatin through inhibiting the Notch1 signaling pathway. Experimental Cell Research 366 161-171. (https://doi.org/10.1016/j. yexcr.2018.03.014)

Braconi C, Kogure T, Valeri N, Huang N, Nuovo G, Costinean S, Negrini M, Miotto E, Croce CM \& Patel T 2011 microRNA-29 can regulate expression of the long non-coding RNA gene MEG3 in hepatocellular cancer. Oncogene 30 4750-4756. (https://doi. org/10.1038/onc.2011.193)

Calin GA, Dumitru CD, Shimizu M, Bichi R, Zupo S, Noch E, Aldler H, Rattan S, Keating M, Rai K, et al. 2002 Frequent deletions and downregulation of micro- RNA genes miR15 and miR16 at 13q14 in chronic lymphocytic leukemia. PNAS 99 15524-15529. (https://doi. org/10.1073/pnas.242606799)

Calin GA, Sevignani C, Dumitru CD, Hyslop T, Noch E, Yendamuri S, Shimizu M, Rattan S, Bullrich F, Negrini M, et al. 2004 Human microRNA genes are frequently located at fragile sites and genomic regions involved in cancers. PNAS 101 2999-3004. (https://doi. org/10.1073/pnas.0307323101)

Cesana M, Cacchiarelli D, Legnini I, Santini T, Sthandier O, Chinappi M, Tramontano A \& Bozzoni I 2011 A long noncoding RNA controls muscle differentiation by functioning as a competing endogenous RNA. Cell 147 358-369. (https://doi.org/10.1016/j. cell.2011.09.028)

Chabre O, Libe R, Assie G, Barreau O, Bertherat J, Bertagna X, Feige JJ \& Cherradi N 2013 Serum miR-483-5p and miR-195 are predictive of recurrence risk in adrenocortical cancer patients. Endocrine-Related Cancer 20 579-594. (https://doi.org/10.1530/ERC-13-0051)

Creevey L, Ryan J, Harvey H, Bray IM, Meehan M, Khan AR \& Stallings RL 2013 MicroRNA-497 increases apoptosis in MYCN amplified neuroblastoma cells by targeting the key cell cycle regulator WEE1. Molecular Cancer 12 23. (https://doi. org/10.1186/1476-4598-12-23)

Erdogan I, Deutschbein T, Jurowich C, Kroiss M, Ronchi C, Quinkler M, Waldmann J, Willenberg HS, Beuschlein F, Fottner C, et al. 2013 The role of surgery in the management of recurrent adrenocortical carcinoma. Journal of Clinical Endocrinology and Metabolism $\mathbf{9 8}$ 181-191. (https://doi.org/10.1210/jc.2012-2559)

Faghihi MA, Zhang M, Huang J, Modarresi F, Van Der Brug MP, Nalls MA, Cookson MR, St-Laurent G \& Wahlestedt C 2010 Evidence for natural antisense transcript-mediated inhibition of microRNA function. Genome Biology 11 R56. (https://doi. org/10.1186/gb-2010-11-5-r56)
Feng T, Shao F, Wu Q, Zhang X, Xu D, Qian K, Xie Y, Wang S, Xu N, Wang Y, et al. 2016 miR-124 downregulation leads to breast cancer progression via LncRNA-MALAT1 regulation and CDK4/E2F1 signal activation. Oncotarget 7 16205-16216. (https://doi.org/10.18632/ oncotarget.7578)

Furuta M, Kozaki K, Tanimoto K, Tanaka S, Arii S, Shimamura T, Niida A, Miyano S \& Inazawa J 2013 The tumor-suppressive miR497-195 cluster targets multiple cell-cycle regulators in hepatocellular carcinoma. PLOS ONE 8 e60155. (https://doi. org/10.1371/journal.pone.0060155)

Glover AR, Zhao JT, Ip JC, Lee JC, Robinson BG, Gill AJ, Soon PS \& Sidhu SB 2015 Long noncoding RNA profiles of adrenocortical cancer can be used to predict recurrence. Endocrine-Related Cancer 22 99-109. (https://doi.org/10.1530/ERC-14-0457)

Graff JR, Konicek BW, Carter JH \& Marcusson EG 2008 Targeting the eukaryotic translation initiation factor $4 \mathrm{E}$ for cancer therapy. Cancer Research 68 631-634. (https://doi.org/10.1158/0008-5472.CAN-075635)

Gu Y, Xiao X \& Yang S 2017 LncRNA MALAT1 acts as an oncogene in multiple myeloma through sponging miR-509-5p to modulate FOXP1 expression. Oncotarget 8 101984-101993. (https://doi. org/10.18632/oncotarget.21957)

Guo F, Li Y, Liu Y, Wang J, Li Y \& Li G 2010 Inhibition of metastasisassociated lung adenocarcinoma transcript 1 in CaSki human cervical cancer cells suppresses cell proliferation and invasion. Acta Biochimica et Biophysica Sinica 42 224-229. (https://doi.org/10.1093/ abbs/gmq008)

Hirata H, Hinoda Y, Shahryari V, Deng G, Nakajima K, Tabatabai ZL, Ishii N \& Dahiya R 2015 Long noncoding RNA MALAT1 promotes aggressive renal cell carcinoma through Ezh2 and interacts with miR-205. Cancer Research 75 1322-1331. (https://doi. org/10.1158/0008-5472.CAN-14-2931)

Hu L, Tang J, Huang X, Zhang T \& Feng X 2018 Hypoxia exposure upregulates MALAT- 1 and regulates the transcriptional activity of PTB-associated splicing factor in A549 lung adenocarcinoma cells. Oncology Letters 16 294-300. (https://doi.org/10.3892/ol.2018.8637)

Itesako T, Seki N, Yoshino H, Chiyomaru T, Yamasaki T, Hidaka H, Yonezawa T, Nohata N, Kinoshita T, Nakagawa M, et al. 2014 The microRNA expression signature of bladder cancer by deep sequencing: the functional significance of the miR-195/497 cluster. PLOS ONE 9 e84311. (https://doi.org/10.1371/journal.pone.0084311)

Ji P, Diederichs S, Wang W, Boing S, Metzger R, Schneider PM, Tidow N, Brandt B, Buerger H, Bulk E, et al. 2003 MALAT-1, a novel noncoding RNA, and thymosin beta4 predict metastasis and survival in earlystage non-small cell lung cancer. Oncogene 22 8031-8041. (https:// doi.org/10.1038/sj.onc.1206928)

Ji Q, Zhang L, Liu X, Zhou L, Wang W, Han Z, Sui H, Tang Y, Wang Y, Liu N, et al. 2014 Long non-coding RNA MALAT1 promotes tumour growth and metastasis in colorectal cancer through binding to SFPQ and releasing oncogene PTBP2 from SFPQ/PTBP2 complex. British Journal of Cancer 111 736-748. (https://doi.org/10.1038/ bjc.2014.383)

Kawaji H \& Hayashizaki Y 2008 Exploration of small RNAs. PLoS Genetics 4 e22. (https://doi.org/10.1371/journal.pgen.0040022)

Kerkhofs TM, Verhoeven RH, Van Der Zwan JM, Dieleman J, Kerstens MN, Links TP, Van De Poll-Franse LV \& Haak HR 2013 Adrenocortical carcinoma: a population-based study on incidence and survival in the Netherlands since 1993. European Journal of Cancer 49 2579-2586. (https://doi.org/10.1016/j.ejca.2013.02.034)

Kong XJ, Duan LJ, Qian XQ, Xu D, Liu HL, Zhu YJ \& Qi J 2015 Tumorsuppressive microRNA-497 targets IKKbeta to regulate NF-kappaB signaling pathway in human prostate cancer cells. American Journal of Cancer Research 5 1795-1804.

Lai MC, Yang Z, Zhou L, Zhu QQ, Xie HY, Zhang F, Wu LM, Chen LM \& Zheng SS 2012 Long non-coding RNA MALAT-1 overexpression predicts tumor recurrence of hepatocellular carcinoma after liver
C) 2019 Society for Endocrinology Published by Bioscientifica Ltd. Printed in Great Britain 
transplantation. Medical Oncology 29 1810-1816. (https://doi. org/10.1007/s12032-011-0004-z)

Leucci E, Patella F, Waage J, Holmstrom K, Lindow M, Porse B, Kauppinen S \& Lund AH 2013 microRNA-9 targets the long noncoding RNA MALAT1 for degradation in the nucleus. Scientific Reports 3 2535. (https://doi.org/10.1038/srep02535)

Li L, Feng T, Lian Y, Zhang G, Garen A \& Song X 2009 Role of human noncoding RNAs in the control of tumorigenesis. PNAS 106 12956-12961. (https://doi.org/10.1073/pnas.0906005106)

Li D, Zhao Y, Liu C, Chen X, Qi Y, Jiang Y, Zou C, Zhang X, Liu S, Wang X, et al. 2011 Analysis of miR-195 and miR-497 expression, regulation and role in breast cancer. Clinical Cancer Research 17 1722-1730. (https://doi.org/10.1158/1078-0432.CCR-10-1800)

Liang H, Zhang J, Zen K, Zhang CY \& Chen X 2013a Nuclear microRNAs and their unconventional role in regulating non-coding RNAs. Protein and Cell 4 325-330. (https://doi.org/10.1007/s13238013-3001-5)

Liang S, Guo R, Zhang Z, Liu D, Xu H, Xu Z, Wang X \& Yang L 2013b Upregulation of the eIF4E signaling pathway contributes to the progression of gastric cancer, and targeting eIF4E by perifosine inhibits cell growth. Oncology Reports 29 2422-2430. (https://doi. org/10.3892/or.2013.2397)

Libe R 2015 Adrenocortical carcinoma (ACC): diagnosis, prognosis, and treatment. Frontiers in Cell and Developmental Biology 3 45. (https:// doi.org/10.3389/fcell.2015.00045)

Libe R, Groussin L, Tissier F, Elie C, Rene-Corail F, Fratticci A, Jullian E, Beck-Peccoz P, Bertagna X, Gicquel C, et al. 2007 Somatic TP53 mutations are relatively rare among adrenocortical cancers with the frequent 17p13 loss of heterozygosity. Clinical Cancer Research 13 844-850. (https://doi.org/10.1158/1078-0432.CCR-06-2085)

Livak KJ \& Schmittgen TD 2001 Analysis of relative gene expression data using real-time quantitative PCR and the 2(-delta delta $\mathrm{C}(\mathrm{T})$ ) method. Methods 25 402-408. (https://doi.org/10.1006/ meth.2001.1262)

Lu MH, Tang B, Zeng S, Hu CJ, Xie R, Wu YY, Wang SM, He FT \& Yang SM 2016 Long noncoding RNA BC032469, a novel competing endogenous RNA, upregulates hTERT expression by sponging miR1207-5p and promotes proliferation in gastric cancer. Oncogene 35 3524-3534. (https://doi.org/10.1038/onc.2015.413)

Lughezzani G, Sun M, Perrotte P, Jeldres C, Alasker A, Isbarn H, Budaus L, Shariat SF, Guazzoni G, Montorsi F, et al. 2010 The European Network for the study of adrenal tumors staging system is prognostically superior to the international union against cancerstaging system: a North American validation. European Journal of Cancer 46 713-719. (https://doi.org/10.1016/j.ejca.2009.12.007)

Luo M, Shen D, Zhou X, Chen X \& Wang W 2013 MicroRNA-497 is a potential prognostic marker in human cervical cancer and functions as a tumor suppressor by targeting the insulin-like growth factor 1 receptor. Surgery 153 836-847. (https://doi.org/10.1016/j. surg.2012.12.004)

Ma L, Zhou Y, Luo X, Gao H, Deng X \& Jiang Y 2017 Long non-coding RNA XIST promotes cell growth and invasion through regulating miR-497/MACC1 axis in gastric cancer. Oncotarget 8 4125-4135. (https://doi.org/10.18632/oncotarget.13670)

Margueron R \& Reinberg D 2010 Chromatin structure and the inheritance of epigenetic information. Nature Reviews: Genetics $\mathbf{1 1}$ 285-296. (https://doi.org/10.1038/nrg2752)

Mele M \& Rinn JL 2016 'Cat's Cradling' the 3D genome by the act of LncRNA transcription. Molecular Cell 62 657-664. (https://doi. org/10.1016/j.molcel.2016.05.011)

Nasr Z, Robert F, Porco JA Jr, Muller WJ \& Pelletier J 2013 eIF4F suppression in breast cancer affects maintenance and progression. Oncogene 32 861-871. (https://doi.org/10.1038/onc.2012.105)

Ozata DM, Caramuta S, Velazquez-Fernandez D, Akcakaya P, Xie H, Hoog A, Zedenius J, Backdahl M, Larsson C \& Lui WO 2011 The role of microRNA deregulation in the pathogenesis of adrenocortical carcinoma. Endocrine-Related Cancer 18 643-655. (https://doi. org/10.1530/ERC-11-0082)

Pan Y, Tong S, Cui R, Fan J, Liu C, Lin Y, Tang J, Xie H, Lin P, Zheng T, et al. 2018 Long non-coding MALAT1 functions as a competing endogenous RNA to regulate vimentin expression by sponging miR30a-5p in hepatocellular carcinoma. Cellular Physiology and Biochemistry 50 108-120. (https://doi.org/10.1159/000493962)

Schteingart DE, Sinsheimer JE, Benitez RS, Homan DF, Johnson TD \& Counsell RE 2012 Structural requirements for mitotane activity: development of analogs for treatment of adrenal cancer. Anticancer Research 32 2711-2720.

Shen L, Li J, Xu L, Ma J, Li H, Xiao X, Zhao J \& Fang L 2012 miR-497 induces apoptosis of breast cancer cells by targeting Bcl-w. Experimental and Therapeutic Medicine 3 475-480. (https://doi. org/10.3892/etm.2011.428)

Soon PS, Libe R, Benn DE, Gill A, Shaw J, Sywak MS, Groussin L, Bertagna X, Gicquel C, Bertherat J, et al. 2008 Loss of heterozygosity of $17 \mathrm{p} 13$, with possible involvement of ACADVL and ALOX15B, in the pathogenesis of adrenocortical tumors. Annals of Surgery $\mathbf{2 4 7}$ 157-164. (https://doi.org/10.1097/SLA.0b013e318153ff55)

Sun R, Qin C, Jiang B, Fang S, Pan X, Peng L, Liu Z, Li W, Li Y \& Li G 2016 Down-regulation of MALAT1 inhibits cervical cancer cell invasion and metastasis by inhibition of epithelial-mesenchymal transition. Molecular Biosystems 12 952-962. (https://doi.org/10.1039/ c5mb00685f)

Tay Y, Kats L, Salmena L, Weiss D, Tan SM, Ala U, Karreth F, Poliseno L, Provero P, Di Cunto F, et al. 2011 Coding-independent regulation of the tumor suppressor PTEN by competing endogenous mRNAs. Cell 147 344-357. (https://doi.org/10.1016/j.cell.2011.09.029)

Tripathi V, Ellis JD, Shen Z, Song DY, Pan Q, Watt AT, Freier SM, Bennett CF, Sharma A, Bubulya PA, et al. 2010 The nuclear-retained noncoding RNA MALAT1 regulates alternative splicing by modulating SR splicing factor phosphorylation. Molecular Cell 39 925-938. (https://doi.org/10.1016/j.molcel.2010.08.011)

Tsang FH, Au SL, Wei L, Fan DN, Lee JM, Wong CC, Ng IO \& Wong CM 2015 Long non-coding RNA HOTTIP is frequently up-regulated in hepatocellular carcinoma and is targeted by tumour suppressive miR125b. Liver International 35 1597-1606. (https://doi.org/10.1111/ liv.12746)

Wang L, Li B, Li L \& Wang T 2013 MicroRNA-497 suppresses proliferation and induces apoptosis in prostate cancer cells. Asian Pacific Journal of Cancer Prevention 14 3499-3502. (https://doi. org/10.7314/APJCP.2013.14.6.3499)

Wang X, Li M, Wang Z, Han S, Tang X, Ge Y, Zhou L, Zhou C, Yuan Q \& Yang M 2015 Silencing of long noncoding RNA MALAT1 by miR101 and miR-217 inhibits proliferation, migration, and invasion of esophageal squamous cell carcinoma cells. Journal of Biological Chemistry 290 3925-3935. (https://doi.org/10.1074/jbc. M114.596866)

Wang SH, Zhang WJ, Wu XC, Weng MZ, Zhang MD, Cai Q, Zhou D, Wang JD \& Quan ZW 2016 The lncRNA MALAT1 functions as a competing endogenous RNA to regulate MCL-1 expression by sponging miR-363-3p in gallbladder cancer. Journal of Cellular and Molecular Medicine 20 2299-2308. (https://doi.org/10.1111/ jcmm.12920)

Wang Y, Zhang Y, Yang T, Zhao W, Wang N, Li P, Zeng X \& Zhang W 2017 Long non-coding RNA MALAT1 for promoting metastasis and proliferation by acting as a ceRNA of miR-144-3p in osteosarcoma cells. Oncotarget 8 59417-59434. (https://doi.org/10.18632/ oncotarget.19727)

Wang H, Wang L, Zhang G, Lu C, Chu H, Yang R \& Zhao G 2018 MALAT1/miR-101-3p/MCL1 axis mediates cisplatin resistance in lung cancer. Oncotarget 9 7501-7512. (https://doi.org/10.18632/ oncotarget.23483)

Wendel HG, De Stanchina E, Fridman JS, Malina A, Ray S, Kogan S, Cordon-Cardo C, Pelletier J \& Lowe SW 2004 Survival signalling by 
Akt and eIF4E in oncogenesis and cancer therapy. Nature $\mathbf{4 2 8}$ 332-337. (https://doi.org/10.1038/nature02369)

Wilusz JE, Sunwoo H \& Spector DL 2009 Long noncoding RNAs: functional surprises from the RNA world. Genes and Development 23 1494-1504. (https://doi.org/10.1101/gad.1800909)

Wu D, Li Y, Zhang H \& Hu X 2017 Knockdown of lncrna PVT1 enhances radiosensitivity in non-small cell lung cancer by sponging Mir-195. Cellular Physiology and Biochemistry 42 2453-2466. (https:// doi.org/10.1159/000480209)

Xiao H, Tang K, Liu P, Chen K, Hu J, Zeng J, Xiao W, Yu G, Yao W, Zhou H, et al. 2015 LncRNA MALAT1 functions as a competing endogenous RNA to regulate ZEB2 expression by sponging miR-200s in clear cell kidney carcinoma. Oncotarget 6 38005-38015. (https:// doi.org/10.18632/oncotarget.5357)
Yan H, Wang Q, Shen Q, Li Z, Tian J, Jiang Q \& Gao L 2018 Identification of potential transcription factors, long noncoding RNAs, and microRNAs associated with hepatocellular carcinoma. Journal of Cancer Research and Therapy 14 S622-S627. (https://doi. org/10.4103/0973-1482.204846)

Zheng S, Cherniack AD, Dewal N, Moffitt RA, Danilova L, Murray BA, Lerario AM, Else T, Knijnenburg TA, Ciriello G, et al. 2016

Comprehensive pan-genomic characterization of adrenocortical carcinoma. Cancer Cell 29 723-736. (https://doi.org/10.1016/j. ccell.2016.04.002)

Zou A, Liu R \& Wu X 2016 Long non-coding RNA MALAT1 is up-regulated in ovarian cancer tissue and promotes SK-OV-3 cell proliferation and invasion. Neoplasma 63 865-872. (https://doi. org/10.4149/neo_2016_605)

Received in final form 12 April 2019

Accepted 13 May 2019

Accepted Preprint published online 13 May 2019
(C) 2019 Society for Endocrinology Published by Bioscientifica Ltd. Printed in Great Britain 